\title{
IoT LoRa-Based Energy Management Information System with RAD Method and Laravel Frameworks
}

\author{
Agus Ramelan, Feri Adriyanto, Chico H. B. Apribowo, Muhammad H. Ibrahim, Meiyanto E. Sulistyo, \\ and Kevin S. Arief
}

\begin{abstract}
This work presents a design and implementation an information system called LoRa-Building Energy Management System (Lo-BEMS). This research proposes an engaging data transmission (read and write), that combines the HTTP and MQTT protocols using third party broker that has monitor and control features for energy usages. Data retrieving uses single LoRa modulation and delivery to the Application Programming Interface (API) in Laravel Framework will then be stopped by the system and stored in the database. The development of this system uses the Rapid Application Development (RAD) method and the Laravel Frameworks. The black-box, UAT, and performance validation test results showed that the information system was running properly and following the objectives.
\end{abstract}

Index Terms - Internet of Things, Information System, Web Design, LoRa, Energy Management.

\section{INTRODUCTION}

$\mathbf{E}$ lectrical energy has become a primary need for humans life $[1,2]$. Therefore, the demand for electrical energy also increases. Uncontrolled and continuous use of electrical energy will cause environmental damage and energy reserves depletion. A Building Energy Management System (BEMS) is a method used to monitor and control the energy requirements of a building, including accommodating electricity usage management [3-5]. The Internet of Things (IoT) approach to the energy sector is also known as the Internet of Energy (IoE) [6]. BEMS consists of sensors, actuators, embedded controllers, connectivity, and information systems. IoT has become part of human activities, both residential and industrial [7,8]. IoT promises to optimize people's daily lives with smart sensors and smart objects that connect and work together $[9,10]$.

Manuscript received January 7, 2021; revised May 29, 2021. Date of publication October 11, 2021. Date of current version October 11, 2021.

This paper was supported by multi years programe of PNBP Research Grant from Universitas Sebelas Maret with the contract numbers 452/UN27.21/PN/2020, and 260/UN27.22/HK.07.00/2021. The authors would like to deliver their sincere gratitude to the Internet of Things (IoT) Laboratory, Faculty of Engineering, Universitas Sebelas Maret.

Authors are with the Electrical Engineering Department, Faculty of Engineering, Universitas Sebelas Maret, Ir Sutami Street number 36A, Kentingan, Surakarta, Central Java, Indonesia, Post Number: 57126 (e-mails agusramelan, feri.adriyanto, hamka, meiyantoekosulistyo@staff.uns.ac.id, chico@ft.uns.ac.id, kscdh6@student.uns.ac.id).

Digital Object Identifier (DOI): 10.24138/jcomss-2021-0003
At present, the application of IoT in energy management combines the application of Artificial Intelligence (AI) based on Big Data [11-14]. The sensor collects data, AI carries out the analysis process, and ends with decision making. More than that, the implementation of $\mathrm{AI}$ in the energy management system has entered the prediction level. Energy usage prediction models are used for precise demand projection so that energy reliability is maintained [15-17]. Research on the application of IoT to energy management is still relevant. The strengthening of smart cities supports this relevance. The smart cities place IoT as a significant role [18]. This work focuses on the application layer, namely building energy management information system. The scope of energy is more limited to electrical energy in a building.

The design of information system is to monitor and control the use of electrical energy so that it is more efficient and economical. This system uses real-time measurement by measuring energy and cost in $\mathrm{kWh}$ (kilowatt-hour). The database then stores these measurements, and the system can display records from a certain period. Additionally, users can export the data in . xls or .csv format. This system is designed as a controller used to manage existing devices. The controller here is done by pressing the on-off button on this system, which then the system will sent the value to the device. It uses an Application Programming Interface (API) to send data from hardware to the database. This information system uses the Laravel Framework, which is very useful in facilitating system development. Laravel is a popular PHP-framework for fullstack development and has a flatter learning curve than all frameworks [19]. Laravel is preferred for the rapid development of large-scale applications [20]. The Laravel Framework has the concept of MVC (Model, View, and Controller). The model is related to the database, the view is related to the user interface, and the controller functions as a control between the model and the view. With this concept, each component will be divided and can be arranged properly. The purpose of using the Laravel framework is that by using this framework, the creation of information systems will be faster and there are several features of the Laravel framework which are very easy to apply [21-23]. The development methodology used in this work is Rapid Application Development (RAD). The purpose of using the RAD method is that it offers speed, adaptability, and evolution [24-26]. 
This work is a development of previous studies. This system is an integration of LoRa-based IoT hardware and a own-built information system. The system uses a combination of Application Programming Interface (API) and Message Queuing Telemetry Transport (MQTT) as a means used to feed data from a hardware device to a server. And this system will be real time so it is very useful for users in monitoring and controlling processes, with the limitation of LoRa network as an unlicensed network.

The rest of the paper is organized as follows. Section II presents proposed methods. Section III describes result and discussion that contain detailed explanation of implementation and testing result. Finally, we conclude this research in section IV.

\section{PROPOSED METHODS}

\section{A. Proposed Architecture System}

Figure 1 is a diagram of the proposed architecture system hardware based on LoRa and real-time monitoring and controlling system. There are four end nodes designed in this study. Each end node has four ACS712 current sensors and a ZMPT101B voltage sensor that are used to measure currents and voltages in loads. In each node, there are 4 channels relay module to control the load usages. These two sensors and relays are connected to the Arduino UNO microcontroller that is integrated with the Dragino LoRa shield to communicate with the LoRa gateway. The LoRa gateway will connect to the Thingspeak server via the internet. The current and voltage data will then be processed by Arduino UNO to obtain the results of electrical energy in Watt-Hour (Wh). Both of these data are sent to the IoT cloud server, Thingspeak. Finally, the results will be displayed in the form of a graph on the field on Thingspeak. Thingspeak is a MQTT broker that can send data to the created information system.

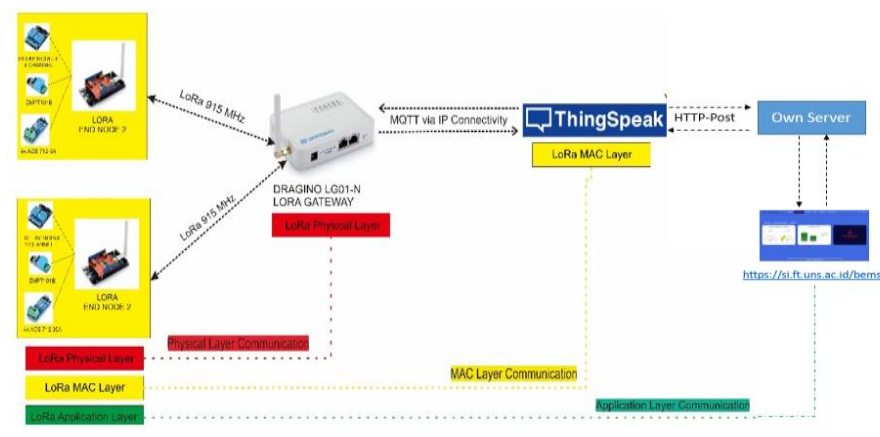

Fig. 1. Proposed system architecture hardware

This work is still in the prototype development stage, therefore it uses a single channel LoRa IoT Gateway (Private LoRa Protocol). The Dragino LGN-01 Gateway has LoRa Wireless specifications 433/868/915/920Mhz, open source openwrt, WiFi interface, ethernet port, USB host port, support 10 100 sensor nodes, and support mutiply working mode such as: MQTT mode, TCP/IP Client mode to fit different requirements for IoT connection. Private LoRa Protocol has some limitations such as doesn't have MAC control/management, the transmission is unencrypted, the gateway only works with specify LoRa end node which runs the same protocol. Therefore that future work, the system will be developed using the LoRaWAN protocol.

This paper describes an engaging data transmission, namely read and write. This work proposes a method that combines the HTTP and MQTT protocols. These two protocols are commonly used in data transmission on IoT. However, the combination of both is still quite interesting to observe and explore.

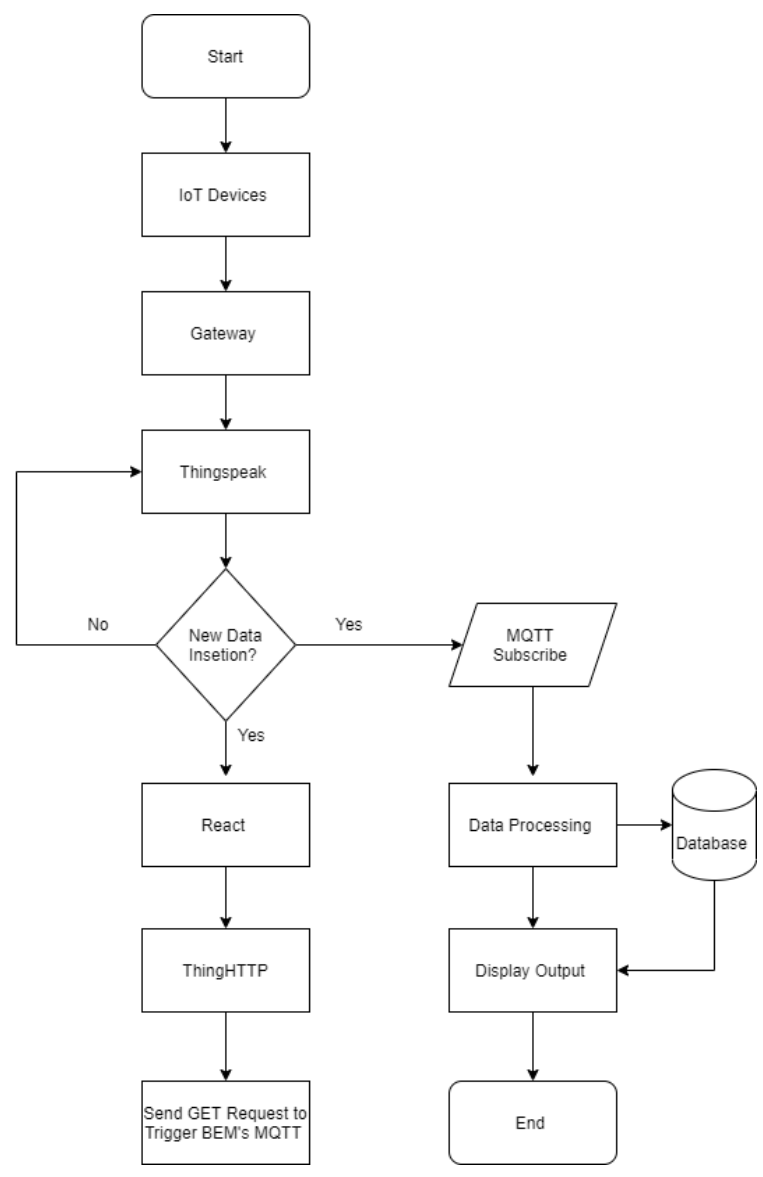

Fig. 2. Proposed flowchart of the data flow

Figure 2 is a diagram of the proposed data flow and the integration of HTTP ang MQTT protocol. The system retrieves data from the hardware that is integrated to Thingspeak. On updating new data, the react feature on Thingspeak will activate ThingHTTP. The ThingHTTP send a GET Request to trigger the MQTT protocol in BEMS Server. The BEMS server performs data processing, selects the data displayed, and stores the data in the database.

\section{B. Software Development}

The BEMS information system is developed by using the Rapid Application Development (RAD). The RAD method allows the user to provide the desired design and the system will be created based on the user's design. And when the user comments on discrepancies in the design, the system will be corrected according to the user's request. The user also determines the data flow that occurs in the information system, by using the API from Thingspeak.

The information system development steps are in figure 3. 
The aim of requirements planning is to identify the needs, limitations, and objective of a system to be built by collecting data from stakeholders. This process consists of developing an Entity Relationship Diagram (ERD) and a Data Flow Diagram (DFD). ERD is a diagram that shows the entities involved in a system and the relationships between these entities. Meanwhile, DFD provides a visual display of the data flow and information from a system.

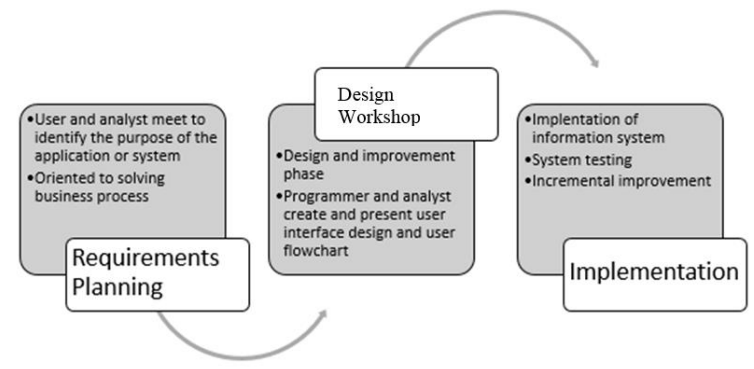

Fig. 3. Information system development step

The design workshop aims to design all activities in the overall system architecture. Besides, it improves understanding of the problem based on the analysis. This process carries out the design and improvement process if there is still a design mismatch between the user and the analyst. The user provides the desired design, and the system will be created. When the user comments on the mismatch design, the system will correct the design according to the user's request. The user also determines the occurrence of the data flow.

\section{Software Testing Method}

Software testing is an element that guarantees the quality of the software and represents the main study of specifications, design, and coding. The software testing method used in this information system is Black Box and User Acceptance Testing (UAT). Black Box is a software testing method used to examine the external work of the system, such as the input/output of the system, the expected results, and the user interfaces whether the system has made according to the design $[27,28]$.

TABLE I

BLACK BOX TEST MODEL

\begin{tabular}{cll}
\hline Number & \multicolumn{1}{c}{ Function } & \multicolumn{1}{c}{ Testing } \\
\hline 1. & Login process & $\begin{array}{l}\text { Entering the user's email and } \\
\text { password then checking the data user } \\
\text { based on the entered input. }\end{array}$ \\
\hline 2. & $\begin{array}{l}\text { Displaying Data } \\
\text { Process }\end{array}$ & $\begin{array}{l}\text { Fetching and displaying data from } \\
\text { the database to a web page. }\end{array}$ \\
\hline 3. & $\begin{array}{l}\text { Updating Data } \\
\text { Process }\end{array}$ & Performing data updates. \\
\hline 4. & $\begin{array}{l}\text { Controlling } \\
\text { Device Process }\end{array}$ & Controlling the device on the system. \\
\hline 5. & Logout process & $\begin{array}{l}\text { Deleting user's session and } \\
\text { redirecting to the dashboard page. }\end{array}$ \\
\hline
\end{tabular}

UAT is a software testing method that involves end-users. The goal is to find out whether the system has been accepted and fulfilled the requirements requested from the end-users [29].
TABLE II

USER APPCEPTANCE FORM

\begin{tabular}{|c|c|c|c|c|c|c|}
\hline Number & Question & SA & $\mathbf{A}$ & $\mathbf{N}$ & D & SD \\
\hline 1 & $\begin{array}{l}\text { This information } \\
\text { system is } \\
\text { attractive. }\end{array}$ & & & & & \\
\hline 2 & $\begin{array}{l}\text { This information } \\
\text { system is } \\
\text { understandable } \\
\text { and feasible. }\end{array}$ & & & & & \\
\hline 3 & $\begin{array}{l}\text { This information } \\
\text { system has a good } \\
\text { performance. }\end{array}$ & & & & & \\
\hline 4 & $\begin{array}{l}\text { This information } \\
\text { system fulfills a } \\
\text { monitoring } \\
\text { function. }\end{array}$ & & & & & \\
\hline 5 & $\begin{array}{l}\text { This information } \\
\text { system fulfills a } \\
\text { controlling } \\
\text { function. }\end{array}$ & & & & & \\
\hline 6 & $\begin{array}{l}\text { This information } \\
\text { system has many } \\
\text { useful features. }\end{array}$ & & & & & \\
\hline 7 & $\begin{array}{l}\text { This information } \\
\text { system monitors } \\
\text { the use of } \\
\text { electrical energy. }\end{array}$ & & & & & \\
\hline 8 & $\begin{array}{l}\text { The feedback for } \\
\text { this information } \\
\text { system. }\end{array}$ & & $\begin{array}{l}\text { Open } \\
\text { answer } \\
\text { from } \\
\text { users. }\end{array}$ & & & \\
\hline
\end{tabular}

Annotation :

SA: strongly agree (5)

A: agree (4)

$\mathrm{N}$ : neutral (3)

D: disagree (2)

SD: strongly disagree (1)

\section{RESULTS AND DISCUSSION}

\section{A. Design and Implementation}

The implementation of the user interface in the information system of BEMS is user design-based. BEMS can be accessed using many types of page browsers.

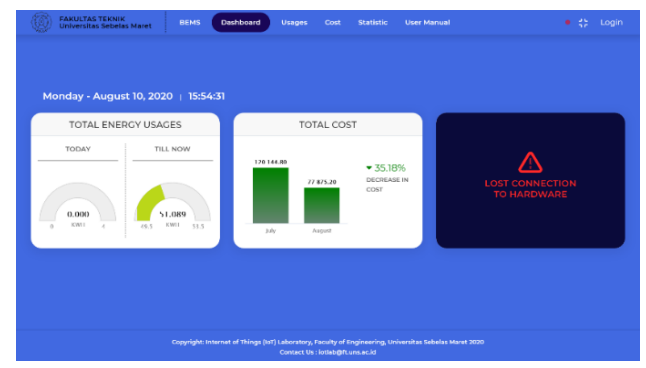

Fig. 4. Dashboard page

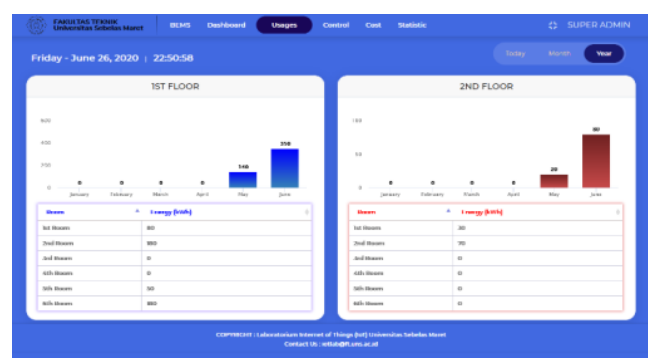

Fig. 5. Usage page 


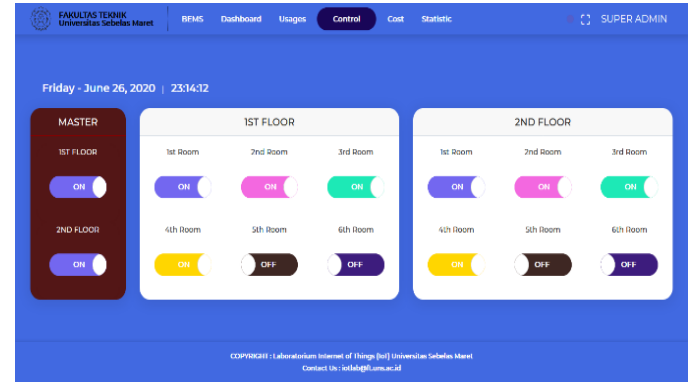

Fig. 6. Control page

The dashboard page is the first page that will be visited by the user. On the dashboard page, there is some information, namely total energy usages, total cost, and running appliances. Each of them is on the card. Meanwhile, the graph will depict the values. The usage page is a page that contains detailed energy usage information. On this page, the user can select three periods of energy use, such as today, month, and year. For each period, it has detailed information.

The control page can only be accessed by admins and super admins. It contains an on/off button for each room on each floor. Besides, it provides an on/off button for master control. The color of each button for each room is different to make it easier for users to distinguish between one and another.

The cost page contains information about costs incurred within a certain period. This information displays graphical data based on a period changed by the user so that the user can see the data for a certain period quickly. When opening the cost page, the default period is one-month. Therefore, the graph will display one-month data.

Statistics page contains information about energy use and costs during a certain period. The period is changeable so that the user can check the data quickly. When opening the statistics page, the default period is one month. Therefore, the graph displays one-month data. Besides, there is also a settings page that can be accessed by admin and super admin only. There are several important information, namely information about the cost per $\mathrm{kWh}$, the controlling feature, the automatic deletion feature, the communication protocol setting, and password changing.

\section{B. Black Box Testing}

The use of Black Box Testing is to determine whether the system runs and functions properly. This software testing is to look for bugs, programming errors, and programming mismatches against the desired goals.

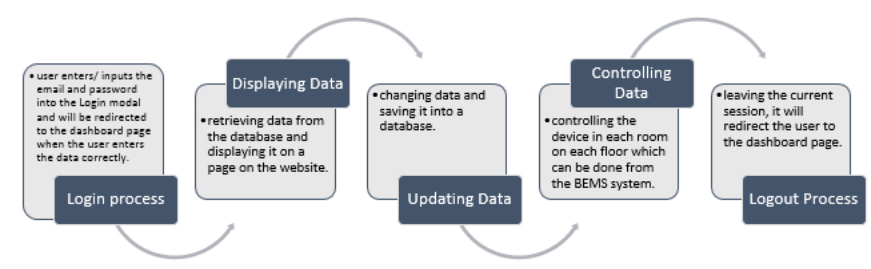

Fig. 7. Black Box Testing Process

The Black Box Testing results stated that the system was running and functioning properly. There were no bugs, programming errors, and programming mismatches.

\section{UAT Testing}

The UAT testing is to determine whether the system runs as expected and meets the objectives. The client or end-user generally carries this test. Each aspect of the questions on the UAT testing will be analyzed using proportion.

This test was conducted on 20 respondents using an online form. The respondents were the user of the information system.

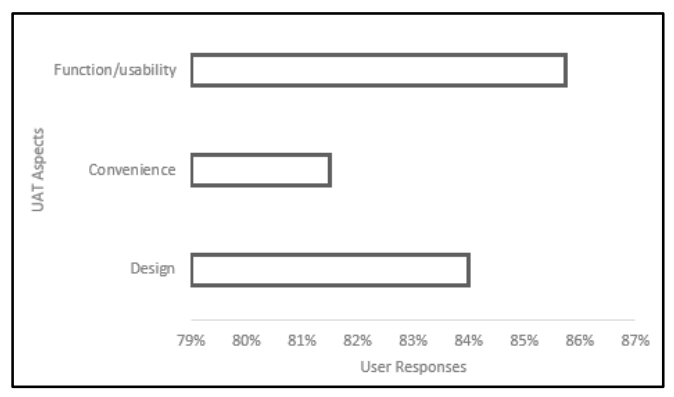

Fig. 8. UAT Result

According to table III and figure 8, the results showed the positive responses of 20 respondents towards the information system. The design aspect (question 1) got $84 \%$. The convenience aspect (question 2-3) obtained $81.5 \%$. The function/ usability aspect (question 4-7) gained $85.75 \%$. The results indicated that the respondents agreed on the given questions.

\section{Data Accuracy Testing}

The data accuracy testing refers to the provisions for sending and receiving data stored in the cloud database. The test is done by comparing the logging data on the serial PC and the logging data on the cloud database. The results of the data accuracy testing are shown in tables IV-VII below.

The tables below show that the average accuracy at A node is $85.10 \%$, B node is $89.19 \%$, C node is $86.07 \%$, and D node is $85.91 \%$. This data is obtained from comparing the measurement results on the power meter, serial monitor, and database. The sensor accuracy is not good enough. However, the focus of this research is to create an energy information system, so it must be ensured that the data stored in the database is the same as the data on the serial monitor. Table IV shows that the information system successfully displays data with the same value as the serial monitor. It proved that the data on the serial monitor has the same value as the data in the database.

TABLE IV

DATA ACCURACY TESTING IN NODES A

\begin{tabular}{cccccc}
\hline Nodes & $\begin{array}{c}\text { Load } \\
\text { Number }\end{array}$ & $\begin{array}{c}\text { Reference } \\
\text { Power } \\
\text { using } \\
\text { Multimeter } \\
\text { (Watt) }\end{array}$ & $\begin{array}{c}\text { Measurement } \\
\text { Power in Serial } \\
\text { Monitor (Watt) }\end{array}$ & $\begin{array}{c}\text { Actual } \\
\text { Power in } \\
\text { Cloud- } \\
\text { Database } \\
\text { (Watt) }\end{array}$ & Error \\
\hline A & 330.00 & 345.68 & 345.524 & 15.52 \\
\cline { 2 - 6 } & 1 & 66.00 & 59.67 & 59.63 & 6.37 \\
\hline 2 & 22.00 & 37.49 & 37.50 & 15.50 \\
\hline 4 & 374.00 & 408.22 & 409.18 & 35.18 \\
\hline & 88.00 & 84.05 & 86.08 & 1.92 \\
\hline & & & & & 85.10 \\
\hline
\end{tabular}


TABLE V

DATA ACCURACY TESTING IN NODES B

\begin{tabular}{cccccc}
\hline Nodes & $\begin{array}{c}\text { Load } \\
\text { Number }\end{array}$ & $\begin{array}{c}\text { Reference } \\
\text { Power } \\
\text { using } \\
\text { Multimeter } \\
\text { (Watt) }\end{array}$ & $\begin{array}{c}\text { Measurement } \\
\text { Power in Serial } \\
\text { Monitor (Watt) }\end{array}$ & $\begin{array}{c}\text { Actual } \\
\text { Power in } \\
\text { Cloud- } \\
\text { Database } \\
\text { (Watt) }\end{array}$ & Error \\
\hline B & 330.00 & 337.05 & 337.05 & 7.05 \\
\cline { 2 - 6 } & 1 & 66.00 & 77.07 & 77.07 & 11.07 \\
\hline 2 & 22.00 & 25.26 & 25.26 & 3.26 \\
\hline 4 & 374.00 & 404.00 & 404.00 & 30.00 \\
\hline 5 & 88.00 & 90.70 & 90.70 & 2.70 \\
\hline
\end{tabular}

TABLE VI

DATA ACCURACY TESTING IN NODES C

\begin{tabular}{cccccc}
\hline Nodes & $\begin{array}{c}\text { Load } \\
\text { Number }\end{array}$ & $\begin{array}{c}\text { Reference } \\
\text { Power } \\
\text { using } \\
\text { Multimeter } \\
\text { (Watt) }\end{array}$ & $\begin{array}{c}\text { Measurement } \\
\text { Power in Serial } \\
\text { Monitor (Watt) }\end{array}$ & $\begin{array}{c}\text { Actual } \\
\text { Power in } \\
\text { Cloud- } \\
\text { Database } \\
\text { (Watt) }\end{array}$ & Error \\
\hline $\mathbf{C}$ & 1 & 330.00 & 292.39 & 292.39 & 37.61 \\
\cline { 2 - 6 } & 2 & 66.00 & 78.60 & 78.60 & 12.60 \\
\hline 3 & 22.00 & 23.02 & 23.02 & 1.02 \\
\hline 4 & 374.00 & 358.76 & 358.76 & 15.24 \\
\hline 5 & 88.00 & 91.18 & 91.18 & 3.18 \\
\hline
\end{tabular}

TABLE VII

DATA ACCURACY TESTING IN NODES D

\begin{tabular}{cccccc}
\hline Nodes & $\begin{array}{c}\text { Load } \\
\text { Number }\end{array}$ & $\begin{array}{c}\text { Reference } \\
\text { Power } \\
\text { using } \\
\text { Multimeter } \\
\text { (Watt) }\end{array}$ & $\begin{array}{c}\text { Measurement } \\
\text { Power in Serial } \\
\text { Monitor (Watt) }\end{array}$ & $\begin{array}{c}\text { Actual } \\
\text { Power in } \\
\text { Cloud- } \\
\text { Database } \\
\text { (Watt) }\end{array}$ & Error \\
\hline D & 330.00 & 304.75 & 304.75 & 25.25 \\
\cline { 2 - 6 } & 1 & 72.56 & 72.56 & 6.56 \\
\hline 2 & 22.00 & 39.77 & 39.77 & 17.77 \\
\hline 4 & 374.00 & 365.17 & 365.17 & 8.83 \\
\hline 5 & 88.00 & 75.98 & 75.98 & 12.02 \\
\hline & & & & 85.91 \\
\hline
\end{tabular}

\section{E. Peformance Testing}

The performance of the BEMS website is checked through a special website, for example Pingdom, which is used to see the performance of a website and provide suggestions on how to improve the performance of the website. On the Pingdom website, the result show that the load time for the BEMS website is fairly good, because it only takes 1.81 seconds for the page to open perfectly.

\section{F. Coverage Gateway Testing}

In this range testing is carried out with the aim of knowing how far LoRa can work. Data is taken from a distance of multiples of $50 \mathrm{~m}$ to $300 \mathrm{~m}$. At each distance, 10 Receiver Signal Strength Indicator (RSSI) data are taken to determine whether the quality of the signal received by the receiver (end node) from the gateway (transmitter) is in the good or bad category.

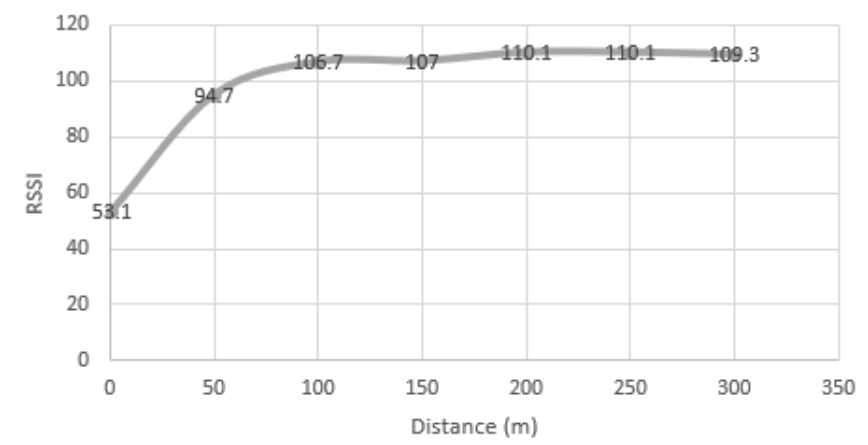

Fig. 9. Receiver Signal Strength Indicator (RSSI) Testing Result

At a distance of 50 meters, the RSSI value obtained is -53.1 $\mathrm{dBm}$ therefore it is included in the very good category. Because the receiver and transmitter are close. At a distance of 50 meters, RSSI $-94.7 \mathrm{dBm}$ therefore it is included in the good category. At a distance of 100 meters, the RSSI is $-106.7 \mathrm{dBm}$ therefore it is included in the bad category. But still can receive the signal well even though some packets are not received. At a distance of 150 meters, the RSSI is $-107 \mathrm{dBm}$ therefore it is included in the bad category. But still can receive the signal well even though some packets are not received. At a distance of 200 meters, the RSSI obtained is $-110.1 \mathrm{dBm}$ therefore it is included in the bad category. But still can receive the signal well even though some packets are not received. At a distance of 250 meters, the RSSI obtained is $-109.3 \mathrm{dBm}$ therefore it is included in the bad category. But still can receive the signal well even though some packets are not received. At a distance of 300 meters, the receiver is no longer able to connect to the transmitter. At this distance, no packets are received by the receiver. Therefore it can be said that at a distance of 300 meters, the receiver and transmitter are disconnected. From the results of the distance testing that has been carried out, the maximum distance for LoRa to work is at a distance of 250 meters, this is due to several factors, including obstacles in the form of buildings and improper placement of the gateway.

\section{CONCLUSION}

The information system is designed by the user with several system improvements based on user requests using the RAD method and Laravel Framework that collects the data from IoT sensors with MQTT and HTTP-Post protocol communication. The information system is implemented in a building with monitoring and controlling energy usages that called as LoRaBuilding Energy Management System (Lo-BEMS). The software testing using a Black-Box and UAT showed that the system function worked properly and got positive responses from the respondents. The UAT showed that the respondents gave their positive responses to the design aspect (84\%), the convenience aspect $(81.5 \%)$, and the function/usability aspect $(85.75 \%)$. The information system successfully displays data with the same value as the serial monitor. It proved that the data on the serial monitor has the same value as the data in the database. 


\section{REFERENCES}

[1] J. Leitão, P. Gil, B. Ribeiro and A. Cardoso, "A Survey on Home Energy Management," in IEEE Access, vol. 8, pp. 5699-5722, 2020

[2] Awanish Kumar, Shashi Ranjan, M. Bharath Kumar Singh, Priyanka Kumari, L. Ramesh, "Electrical Energy Audit in Residential House", in Procedia Technology, Volume 21, Pages 625-630, 2015

[3] M. A. Hannan et al., "A Review of Internet of Energy Based Building Energy Management Systems: Issues and Recommendations," in IEEE Access, vol. 6, pp. 38997-39014, 2018

[4] S. Lee, B. Kwon and S. Lee, "Joint Energy Management System of Electric Supply and Demand in Houses and Buildings," in IEEE Transactions on Power Systems, vol. 29, no. 6, pp. 2804-2812, Nov. 2014

[5] Mehreen S. Gul, Sandhya Patidar, "Understanding the energy consumption and occupancy of a multi-purpose academic building", in Energy and Buildings, Volume 87,Pages 155-165, 2015

[6] C. K. Metallidou, K. E. Psannis and E. A. Egyptiadou, "Energy Efficiency in Smart Buildings: IoT Approaches," in IEEE Access, vol. 8, pp. 63679 63699,2020

[7] D. Minoli, K. Sohraby and B. Occhiogrosso, "IoT Considerations, Requirements, and Architectures for Smart Buildings-Energy Optimization and Next-Generation Building Management Systems," in IEEE Internet of Things Journal, vol. 4, no. 1, pp. 269-283, Feb. 2017

[8] O. Said, Z. Al-Makhadmeh and A. Tolba, "EMS: An Energy Managemen Scheme for Green IoT Environments," in IEEE Access, vol. 8, pp. 4498344998, 2020

[9] S. L. Keoh, S. S. Kumar and H. Tschofenig, "Securing the Internet of Things: A Standardization Perspective," in IEEE Internet of Things Journal, vol. 1, no. 3, pp. 265-275, June 2014

[10] C. Lin, D. Deng and a. L. Lu, "Many-Objective Sensor Selection in IoT Systems," in IEEE Wireless Communications, vol. 24, no. 3, pp. 40-47, June 2017

[11] A. R. Al-Ali, I. A. Zualkernan, M. Rashid, R. Gupta and M. Alikarar, "A smart home energy management system using IoT and big data analytics approach," in IEEE Transactions on Consumer Electronics, vol. 63, no. 4 pp. 426-434, November 2017

[12] G. Bedi, G. K. Venayagamoorthy, R. Singh, R. R. Brooks and K. Wang, "Review of Internet of Things (IoT) in Electric Power and Energy Systems," in IEEE Internet of Things Journal, vol. 5, no. 2, pp. 847-870, April 2018

[13] A. R. Al-Ali, I. A. Zualkernan, M. Rashid, R. Gupta and M. Alikarar, "A smart home energy management system using IoT and big data analytics approach," in IEEE Transactions on Consumer Electronics, vol. 63, no. 4 , pp. 426-434, November 2017

[14] W. Li, T. Logenthiran, V. Phan and W. L. Woo, "Implemented IoT-Based Self-Learning Home Management System (SHMS) for Singapore," in IEEE Internet of Things Journal, vol. 5, no. 3, pp. 2212-2219, June 2018

[15] G. Bedi, G. K. Venayagamoorthy and R. Singh, "Development of an IoT Driven Building Environment for Prediction of Electric Energy Consumption," in IEEE Internet of Things Journal, vol. 7, no. 6, pp. 4912 4921, June 2020

[16] S. H. Lee, T. Lee, S. Kim and S. Park, "Energy Consumption Prediction System Based on Deep Learning with Edge Computing," 2019 IEEE 2nd International Conference on Electronics Technology (ICET), Chengdu, China, pp. 473-477, 2019

[17] D. H. Tran, E. Sanchez and M. H. Nazari, "Model Predictive Energy Management for Building Microgrids with IoT-based Controllable Loads," 2019 North American Power Symposium (NAPS), Wichita, KS, USA, pp. 1-6, 2019

[18] A. Zanella, N. Bui, A. Castellani, L. Vangelista and M. Zorzi, "Internet of Things for Smart Cities," in IEEE Internet of Things Journal, vol. 1, no. 1, pp. 22-32, Feb. 2014

[19] Majida Laaziri, Khaoula Benmoussa, Samira Khoulji, Kerkeb Mohamed Larbi, Abir El Yamami, "A comparative study of laravel and symfony PHP frameworks" International Journal of Electrical and Computer Engineering (IJECE) Vol. 9, No. 1, pp. 704 712, February 2019

[20] Majida Laaziri, Khaoula Benmoussa, Samira Khoulji, Mohamed Larb Kerkeb, "A Comparative study of PHP frameworks performance", in Procedia Manufacturing, Volume 32, Pages 864-871, 2019

[21] Andri Sunardi, Suharjito, "MVC Architecture: A Comparative Study Between Laravel Framework and Slim Framework in Freelancer Project Monitoring System Web Based", in Procedia Computer Science, Volume 157, Pages 134-141, 2019

[22] Mohammed Thakir Mahmood, Osama Ibrahem Ashour, Osman.Ucan, Oğuz Bayat, "Design and Implementation of Web Based For Intermediate
Online Shop with Laravel Framework", in International Journal of Computer Science and Mobile Computing, Vol. 8, Issue. 3, pg.124 - 133, March 2019

[23] Dragos-Paul Pop, Adam Altar, "Designing an MVC Model for Rapid Web Application evelopment", in Procedia Engineering, Volume 69, Pages 1172-1179, 2014

[24] K. Rapley, "RAD or TRAD or both? The future of software development," IEE Colloquium on Will Tickit and ISO 9000 Survive Rapid Application Development?, London, UK, 1995, pp. 3/1-3/2

[25] P. Beynon-Davies and S. Holmes, "Integrating rapid application development and participatory design," in IEE Proceedings - Software, vol. 145, no. 4, pp. 105-112, Aug. 1998

[26] B. Prashanth Kumar and Y. Prashanth, "Improving the Rapid Application Development process model," 2014 Conference on IT in Business, Industry and Government (CSIBIG), Indore, pp. 1-3, 2014

[27] C. U. Munoz, "An approach to software product testing," in IEEE Transactions on Software Engineering, vol. 14, no. 11, pp. 1589-1596, Nov. 1988

[28] M. Leotta et al., "An acceptance testing approach for Internet of Things systems," in IET Software, vol. 12, no. 5, pp. 430-436, 102018

[29] L. Yu et al., "Towards Call for Testing: An Application to User Acceptance Testing of Web Applications," 2009 33rd Annual IEEE International Computer Software and Applications Conference, Seattle, WA, 2009, pp. 166-171

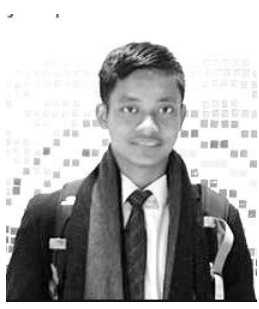

Agus Ramelan was born in Wonogiri, Central Java, Indonesia in 1992. He received the B.S. degrees in industrial electronics from Universitas Pendidikan Indonesia and M.S. degrees in control system from the Instititut Teknologi Bandung in 2018. During the M.S. degrees, he was a Research Assistant with the Computer Systems \& Control Laboratory. Since 2019, he has been a Lecturer with the Electrical Engineering Department, Universitas Sebelas Maret. His research interests include control system, internet of things, and smart grid. He is a Head of IoT Laboratory in Faculty of Engineering, Universitas Sebelas Maret.

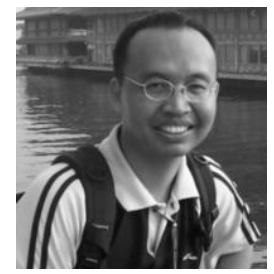

Feri Adriyanto is an Assistant Professor in Microelectronics. He is an expert in semiconductor nanomaterials for electronic devices. Since 2015, he has been at the Microelectronics and Nanotechnology-Shamsuddin Research Centre at Universiti Tun Hussein Onn Malaysia. From Nov 2010 to Dec 2013, he visited Microsystems and Nanotechnology Lab. at the University of Oslo, Norway as a visiting researcher. He worked in flexible transparent $\mathrm{ZnO}$ for TFTs at the Institute of Microelectronics, NCKU Taiwan. He is a Head of Electrical Engineering Departement in Faculty of Engineering, Universitas Sebelas Maret.

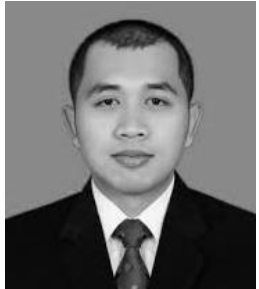

Chico Hermanu Brillianto Apribowo is a lecturer and researcher in Electrical Engineering Departement, Universitas Sebelas Maret. He received the B.S. degrees in Power Engineering from Institut Teknologi Sepuluh September and M.S. degrees in Power Engineering from the Universitas Gajah Mada. His research interests include Renewable Energy Technologies, Power Electronics, Power Converters Power System Modelling, Power Systems, Microgrids Optimization, Controlling. He is a Head of Power System and Energy Converstion Laboratory in Faculty of Engineering, Universitas Sebelas Maret.

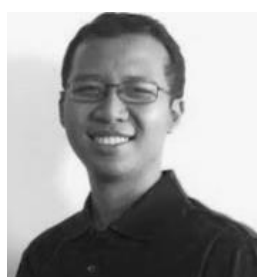

Muhammad Hamka Ibrahim is a lecturer and researcher in Electrical Engineering Departement, Universitas Sebelas Maret. He received the B.S degrees in Telecommunication Engineering from Institut Teknologi Bandung and M.S. degrees in IT Convergenece Engineering from the Kumoh National Institute of Technology. He is a Engineering Educato with a demonstrated history of working in the high 
tech company. Having strong research background in VLSI and Wireless Technologies. Skilled in Embedded System, Computer Vision and Data Acquisition. He is a Head of Telecommunication and Signal Processing Laboratory in Faculty of Engineering, Universitas Sebelas Maret.

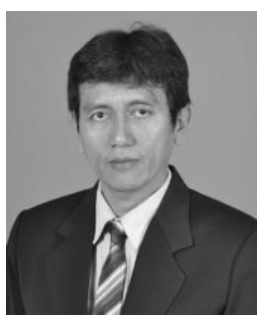

Meiyanto Eko Sulistyo is a lecturer and researcher in Electrical Engineering Departement, Universitas Sebelas Maret. He received the B.S. degrees and M.S. degrees in Electrical Engineering from Universitas Gajah Mada. His research interests Communication Engineering, Electrical Engineering, Computer Engineering. He is a Head of Computer Laboratory in Faculty of Engineering, Universitas Sebelas Maret.

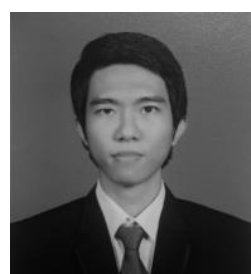

Kevin Sebastian Arief is an assistant researcher in Electrical Engineering Departement, Universitas Sebelas Maret. He received the B.S. degrees in Electrical Engineering from Universitas Sebelas Maret. His research interests include information system, Electrical Engineering, and Computer Engineering. 